\title{
Quantifying the missing link between forest albedo and productivity in the boreal zone
}

\author{
Aarne Hovi $^{1}$, Jingjing Liang ${ }^{2}$, Lauri Korhonen ${ }^{3}$, Hideki Kobayashi ${ }^{4}$, and Miina Rautiainen ${ }^{1,5}$ \\ ${ }^{1}$ Department of Built Environment, School of Engineering, Aalto University, P.O. Box 15800, 00076 Aalto, Finland \\ ${ }^{2}$ School of Natural Resources, West Virginia University, P.O. Box 6125, Morgantown, WV 26505, USA \\ ${ }^{3}$ School of Forest Sciences, University of Eastern Finland, P.O. Box 111, 80101 Joensuu, Finland \\ ${ }^{4}$ Department of Environmental Geochemical Cycle Research, Japan Agency for Marine-Earth Science and Technology, \\ 3173-25, Showa-machi, Kanazawa-ku, Yokohama, 236-0001, Japan \\ ${ }^{5}$ Department of Radio Science and Engineering, School of Electrical Engineering, Aalto University, P.O. Box 13 000, \\ 00076 Aalto, Finland
}

Correspondence to: Aarne Hovi (aarne.hovi@aalto.fi)

Received: 13 May 2016 - Published in Biogeosciences Discuss.: 23 May 2016

Revised: 17 October 2016 - Accepted: 19 October 2016 - Published: 3 November 2016

\begin{abstract}
Albedo and fraction of absorbed photosynthetically active radiation (FAPAR) determine the shortwave radiation balance and productivity of forests. Currently, the physical link between forest albedo and productivity is poorly understood, yet it is crucial for designing optimal forest management strategies for mitigating climate change. We investigated the relationships between boreal forest structure, albedo and FAPAR using a radiative transfer model called Forest Reflectance and Transmittance model FRT and extensive forest inventory data sets ranging from southern boreal forests to the northern tree line in Finland and Alaska ( $N=1086$ plots). The forests in the study areas vary widely in structure, species composition, and human interference, from intensively managed in Finland to natural growth in Alaska. We show that FAPAR of tree canopies $\left(\right.$ FAPAR $_{\text {CAN }}$ ) and albedo are tightly linked in boreal coniferous forests, but the relationship is weaker if the forest has broadleaved admixture, or if canopies have low leaf area and the composition of forest floor varies. Furthermore, the functional shape of the relationship between albedo and FAPAR ${ }_{\text {CAN }}$ depends on the angular distribution of incoming solar irradiance. We also show that forest floor can contribute to over $50 \%$ of albedo or total ecosystem FAPAR. Based on our simulations, forest albedos can vary notably across the biome. Because of larger proportions of broadleaved trees, the studied plots in Alaska had higher albedo (0.141-0.184) than those in Finland (0.136-0.171) even though the albedo of
\end{abstract}

pure coniferous forests was lower in Alaska. Our results reveal that variation in solar angle will need to be accounted for when evaluating climate effects of forest management in different latitudes. Furthermore, increasing the proportion of broadleaved trees in coniferous forests is the most important means of maximizing albedo without compromising productivity: based on our findings the potential of controlling forest density (i.e., basal area) to increase albedo may be limited compared to the effect of favoring broadleaved species.

\section{Introduction}

Forest management practices, such as thinning and logging, alter the spatial, structural, and species composition of forests. Through an altered albedo and productivity, these management practices may cause profound impacts on climate. Because forest structure and species composition influence albedo, managing forests to increase albedo is a potential means of maximizing the climate cooling effects of forests (Bright et al., 2014; Alkama and Cescatti, 2016; Naudts et al., 2016). However, if forest management practices are altered in order to maximize albedo, productivity may be compromised, which would result in reduced carbon uptake as well as reduced timber production and corresponding economic losses. There is an urgent need to understand 
how forest management practices change forest albedo, and how forest albedo and productivity are interconnected.

Being the world's largest land-based biome, the boreal forest zone consists of vast forest areas under various human interference levels, from natural growth to intense silvicultural management. The biome plays an important role in controlling the global carbon and energy balances. It is estimated that the boreal forests comprise $32 \%$ of the total carbon in the world's forests, and account for a significant portion of the carbon uptake (Pan et al., 2011). In addition, the albedo of boreal forests varies considerably by forest structure, phenology, and snow cover (e.g., Ni and Woodcock, 2000; Kuusinen et al., 2012, 2016; Bright et al., 2013).

Previous studies based on local in situ measurements, or remote sensing data for local to regional study areas, have shown that boreal forest albedo is influenced by tree species, with broadleaved species rendering higher albedos than coniferous (Lukeš et al., 2013a; Kuusinen et al., 2014). Albedo of open areas or that of the forest floor is usually higher than in the canopy areas (Bright et al., 2014; Kuusinen et al., 2014), except for burned sites (Amiro et al., 2006). A declining trend in albedo with forest height or age has been observed for coniferous forests (Amiro et al., 2006; Kirschbaum et al., 2011; Bright et al., 2013; Kuusinen et al., 2016) and may be at least partly explained by the increasing leaf area index (LAI) and, thus, reduced contribution of the forest floor on albedo as the forests mature. Similarly, a declining trend in albedo with canopy density has been observed (Lukeš et al., 2013a).

Gross primary productivity of vegetation can be approximated by FAPAR, i.e., the fraction of photosynthetically active radiation (PAR, 400-700 $\mathrm{nm}$ ) absorbed by the vegetation canopy (Gobron and Verstraete, 2009), because photosynthesis is ultimately driven by the available solar energy. FAPAR is useful in monitoring and comparing productivity both spatially and temporally, especially in the absence of accurate growth and yield models, although it should be noted that productivity is affected also by light use efficiency (LUE), i.e., the efficiency by which plants convert the solar energy into photosynthesis products (Monteith, 1972). The main determinants of forest canopy FAPAR are leaf area index (LAI) and the directionality of incoming solar radiation (Majasalmi et al., 2014), because they determine the fraction of PAR interceptable by the canopy. Similarly to albedo, boreal forest FAPAR may differ by tree species (Roujean et al., 1999; Steinberg et al., 2006; Chasmer et al., 2008; Serbin et al., 2013; Majasalmi et al., 2015) and stand age (Serbin et al., 2013), as both species and age are likely to influence the LAI of the canopy.

Estimation methods set limits for the information that can be obtained on the spatial and temporal variation of albedo and FAPAR. In situ measurements are accurate and can be directly linked with field-measured forest structure. On the other hand, they are extremely tedious and cannot cover large variations in forest structure. Satellite data provide ample coverage of varying forest structures and wide spatial extent but may compromise spatial resolution and detail in the characterization of forest structure. In addition, neither local albedo measurements nor satellite-based albedo products can explain the causality between small-scale environmental management scenarios and changes in albedo or FAPAR. Radiative transfer models offer a solution to these problems: forest radiative transfer models are a powerful tool for linking quantitative changes in vegetation structure to albedo or FAPAR for large geographical regions. The models are parameterized using mathematical descriptions of canopy structure (e.g., LAI, tree height, crown dimensions, stand density), optical properties of foliage and forest floor, and spectral and angular properties of incoming radiation. Using these models, the albedo and FAPAR of a forest can be calculated from readily measurable variables such as forest structure and leaf optical properties.

To our knowledge only one study has examined the relation between forest albedo and FAPAR (Lukeš et al., 2016). In that study, coarse resolution satellite products (MODIS) were used and one geographical area (Finland) was studied. Furthermore, previous studies on forest structure and albedo have mainly focused on local geographical scales (e.g., Finland and Norway, but see Kuusinen et al. (2013) for comparison between Finland and Canada). Comparison of the relationships between forest structure, albedo, and FAPAR has not been performed across the biome, i.e., including both European and North American boreal forests which have very different natural structures and forest management scenarios. Due to the large north-south gradient and consequent structural diversity of forests in the boreal zone, the impact of forest management on albedo cannot be expected to be the same.

Here we report results from quantifying the links between boreal forest structure, albedo, and FAPAR ranging from southern boreal forests to the northern tree line using detailed, large forest inventory data sets from Finland and Alaska ( $N=1086$ plots). The forests in the study areas vary widely in structure, species composition, and human interference, from intensively managed (regularly thinned) forests in Finland to natural growth in Alaska. Using a radiative transfer modeling approach, we quantify the effects of forest structure and species composition on albedo and FAPAR in order to answer how forest management practices can be optimized for climate change mitigation. The significant benefit of the modeling approach is that it enables the study of structurally varying forests over large geographical areas, without compromising detail in the forest structure representation or in the spatial resolution. Our study is therefore the first intercontinental study connecting albedo and productivity of boreal forests, using accurate ground reference data. 

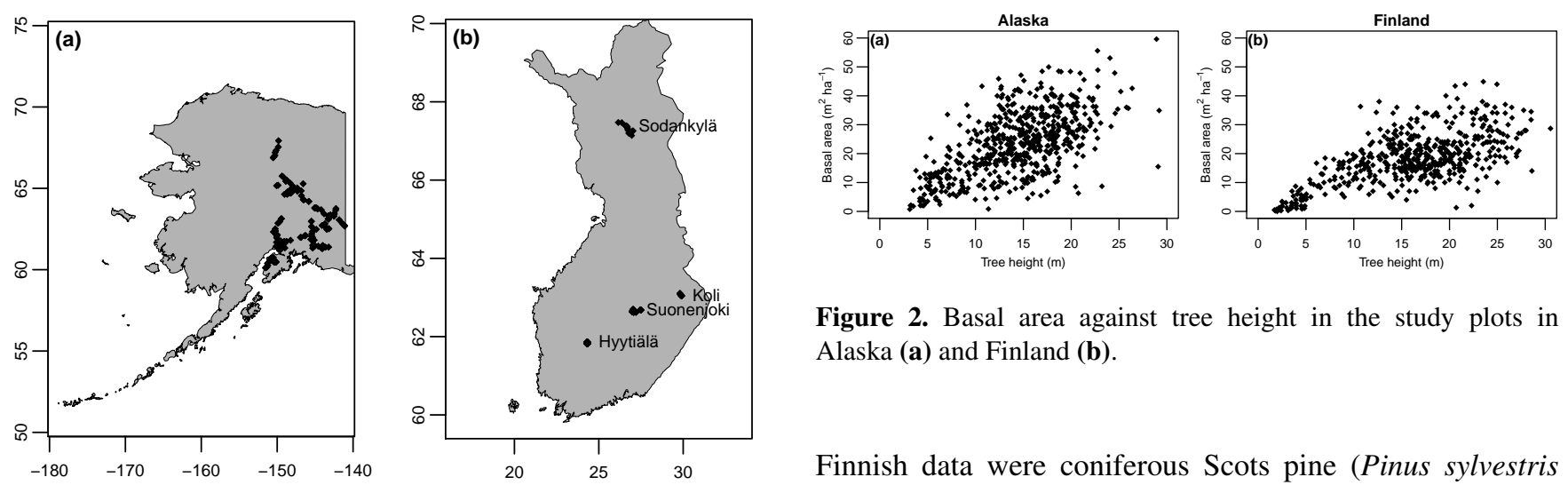

Figure 2. Basal area against tree height in the study plots in Alaska (a) and Finland (b).

Figure 1. Location of the field plots.

\section{Materials and methods}

\subsection{Study areas and field plots}

This study is based on 1086 field plots located in Alaska (United States) and Finland, between northern latitudes of 60 and $68^{\circ}$. At these latitudes, solar zenith angle (SZA) at solar noon at midsummer ranges from 37 to $45^{\circ}$, and the annual average from 69 to $72^{\circ}$.

The field plots in Alaska $(N=584)$ were permanent sample plots established as part of the Co-operative Alaska Forest Inventory that aims at long-term monitoring of forest conditions and dynamics (Packee et al., 2010; Malone et al., 2009). The plots were scattered in interior and south-central Alaska across a region of about $300000 \mathrm{~km}^{2}$, from Fairbanks in the north to the Kenai Peninsula in the south (Fig. 1, for more details see Liang et al., 2015). Some of the plots were measured more than once. We used only the most recent measurement of each plot. The plots in Finland $(N=502)$ were temporary or permanent sample plots. They were located at four separate sites: Hyytiälä (Majasalmi et al., 2015), Koli, Sodankylä, and Suonenjoki (Korhonen, 2011), ranging from southern to northern Finland (Fig. 1). Species-level attributes, including the number of stems per hectare, basal area, mean diameter at breast height, tree height, and length of living crown, were available for the plots. Basal area, the total cross-sectional area of stemwood $\left(\mathrm{m}^{2} \mathrm{ha}^{-1}\right)$ at breast height (i.e., at 1.3 or $1.37 \mathrm{~m}$ ), is a common measure of stand density in forest inventories and, combined with information on tree height, is used as an indicator of need for silvicultural thinning operations.

Tree species in the Alaskan data were coniferous black spruce (Picea mariana (Mill.) B. S. P.) and white spruce (Picea glauca (Moench) Voss), and broadleaved quaking aspen (Populus tremuloides Michx.), black cottonwood or balsam poplar (Populus trichocarpa Torr. and Gray, P. balsamifera L.), Alaskan birch (Betula neoalaskana Sarg.), and Kenai birch (Betula kenaica W. H. Evans). Tree species in the

Finnish data were coniferous Scots pine (Pinus sylvestris L.) and Norway spruce (Picea abies (L.) H. Karst), and broadleaved species comprising mainly of silver and downy birch (Betula pendula Roth, B. pubescens Ehrh.). The birches accounted for $89 \%$ of the basal area of the broadleaved species in Finland. The forest variables in the study plots are shown in Table 1, for all plots and separately for plots dominated by one species. The Alaskan and Finnish forests differed in structure. The forests in Alaska were on average denser in terms of basal area (Fig. 2), and contained a larger proportion of broadleaved species than the Finnish forests (Table 1). Managed forests in Finland, which our plots mainly represent, are normally thinned 1-3 times during the rotation period so that coniferous species are favored. In our plots from Alaska, on the other hand, no thinnings were applied.

The plots in Finland were classified into six site fertility classes in the field, according to a local site type classification system (Cajander, 1949). We re-classified the original number of six fertility classes into three: "xeric", "mesic", and "herb-rich". The cover of grasses is highest in the herb-rich, and decreases towards the xeric type. The cover of lichens, on the other hand, increases towards the xeric type (Hotanen et al., 2013). In the Alaskan plots no site fertility estimate was available but the cover of each species in the forest floor had been estimated. We labeled the plots as lichenor grass-dominated if either the cover of lichens or the total cover of herbs, grasses, rush, sedges, and fern was over $50 \%$. The remaining plots were dominated by shrubs and mosses or were a mixture of all species groups. Hereafter we refer to these forest floor types as "grass", "shrub/moss", and "lichen". Forest floor types did not differ notably between forests dominated by different tree species, except for Scots pine forests in Finland, which were often found in the xeric type and were almost nonexistent in the herb-rich type (Table 2).

\subsection{Albedo and FAPAR simulations}

\subsubsection{Simulation model}

We simulated albedo and FAPAR using a radiative transfer model called Forest Reflectance and Transmittance model 
Table 1. Mean (standard deviation) of forest variables by dominant tree species in Alaska and Finland. The species dominance was determined by basal area proportion: if the basal area of one of the species exceeded $80 \%$ of the total basal area, the plot was considered to be dominated by that species. The remaining plots were labeled as mixed.

\begin{tabular}{lrrrrrrr}
\hline Tree species & $\begin{array}{r}\text { Number } \\
\text { of plots }\end{array}$ & $\begin{array}{r}\text { Stems per } \\
\text { hectare }\end{array}$ & $\begin{array}{r}\text { Diameter at breast } \\
\text { height }(\mathrm{cm})^{1}\end{array}$ & $\begin{array}{r}\text { Height } \\
(\mathrm{m})\end{array}$ & $\begin{array}{r}\text { Crown ratio } \\
(\%)^{2}\end{array}$ & $\begin{array}{r}\text { Basal area } \\
\left(\mathrm{m}^{2} \mathrm{ha}^{-1}\right)\end{array}$ & $\begin{array}{r}\text { Effective LAI } \\
\left(\mathrm{m}^{2} \mathrm{~m}^{-2}\right)^{3}\end{array}$ \\
\hline Alaska & & & & & & & \\
\hline Black spruce & 70 & $2361(1542)$ & $9.3(3.8)$ & $7.3(3.2)$ & $69(11)$ & $14.6(9.3)$ & $1.0(0.6)$ \\
White spruce & 124 & $806(653)$ & $21.3(7.9)$ & $14.7(5.2)$ & $74(9)$ & $22.8(13.1)$ & $2.4(1.3)$ \\
Quaking aspen & 22 & $1572(916)$ & $15.8(5.1)$ & $13.9(3.5)$ & $37(7)$ & $26.0(8.8)$ & $2.8(0.9)$ \\
Black cottonwood/ & 8 & $672(658)$ & $35.1(14.7)$ & $20.5(5.8)$ & $62(11)$ & $34.8(14.5)$ & $2.7(1.1)$ \\
balsam poplar & & & & & & & \\
Birches & 84 & $873(662)$ & $22.6(8.4)$ & $17.5(2.9)$ & $58(11)$ & $25.1(8.1)$ & $3.2(1.4)$ \\
Mixed & 276 & $1082(1131)$ & $22.0(8.3)$ & $15.1(3.9)$ & $62(12)$ & $25.2(10.1)$ & $2.7(1.2)$ \\
All & 584 & $1160(1139)$ & $20.3(9.0)$ & $14.4(4.9)$ & $64(13)$ & $23.6(11.0)$ & $2.5(1.3)$ \\
\hline Finland & & & & & & & \\
\hline Scots pine & 184 & $1165(1301)$ & $18.0(8.5)$ & $14.7(6.4)$ & $51(16)$ & $15.9(7.7)$ & $1.1(0.5)$ \\
Norway spruce & 115 & $980(1014)$ & $19.7(8.9)$ & $16.6(6.9)$ & $68(15)$ & $19.8(9.4)$ & $2.4(1.1)$ \\
Broadleaved & 23 & $1409(1419)$ & $13.6(7.1)$ & $13.9(6.0)$ & $62(16)$ & $12.6(7.1)$ & $1.9(1.2)$ \\
Mixed & 180 & $1094(1782)$ & $20.5(8.0)$ & $17.2(5.8)$ & $58(14)$ & $20.3(9.1)$ & $2.2(1.1)$ \\
All & 502 & $1109(1444)$ & $19.1(8.5)$ & $16.0(6.4)$ & $58(16)$ & $18.2(8.9)$ & $1.8(1.1)$ \\
\hline
\end{tabular}

${ }^{1}$ Definition of breast height differed between Alaska $(1.37 \mathrm{~m})$ and Finland $(1.3 \mathrm{~m}) .{ }^{2}$ Ratio of the length of living crown to tree height. ${ }^{3}$ Not measured in the field. The values are calculated by the FRT model.

Table 2. Number of study plots by dominant tree species and forest floor type. The species dominance was determined by basal area proportion: if the basal area of one of the species exceeded $80 \%$ of the total basal area, the plot was considered to be dominated by that species.

\begin{tabular}{lrrr}
\hline Tree species & \multicolumn{3}{c}{ Forest floor } \\
\cline { 2 - 4 } & Grass & Shrub/moss & Lichen \\
\hline Black spruce & 8 & 60 & 2 \\
White spruce & 13 & 111 & 0 \\
Quaking aspen & 4 & 18 & 0 \\
Black cottonwood/ & 2 & 6 & 0 \\
balsam poplar & & & \\
Birches & 23 & 61 & 0 \\
Mixed & 40 & 236 & 0 \\
All & 90 & 492 & 2 \\
\hline & Herb-rich & Mesic & Xeric \\
\hline Scots pine & 2 & 145 & 37 \\
Norway spruce & 28 & 86 & 1 \\
Broadleaved & 8 & 14 & 1 \\
Mixed & 26 & 152 & 2 \\
All & 64 & 397 & 41 \\
\hline
\end{tabular}

(FRT). It was originally published by Nilson and Peterson (1991) and later modified by Kuusk and Nilson (2000). FRT is a hybrid type model that combines geometric-optical and radiative-transfer-based sub-models for modeling the first- and higher-order scattering components, respectively. The model has been intercompared and validated within the RAdiative transfer Model Intercomparison exercise (RAMI) several times, including validation of both reflected and transmitted fractions of radiation. The results from these tests are publicly available online (Joint Research Centre, 2016) and reported in peer-reviewed scientific papers (e.g., Widlowski et al., 2007). In this study, we used a version of FRT modified by Mõttus et al. (2007). The advantage of FRT is that it can be parameterized using standard forest inventory data, utilizing the allometric relations of forest variables to foliage biomass and crown dimensions. This was important because field measurements of biophysical variables (e.g., LAI) are not commonly available, as was also the case in our study plots.

FRT simulates stand-level bidirectional reflectance and transmittance factors (BRF, BTF) of a forest at specified wavelengths. A $12 \times 12$ Gauss-Legendre cubature was used to integrate the simulated BRF and BTF values over the upper and lower hemispheres, respectively. This resulted in upward scattered and downwelling (directly transmitted or downward scattered) fractions of incoming radiation. The former is observed on top of, and the latter below, the tree canopy. These fractions were then used to calculate the shortwave broadband albedo and FAPAR. The simulations were carried out at $5 \mathrm{~nm}$ resolution, and the albedo simulations covered a spectral region of 400-2100 nm which corresponds to the region from which input data were available (see Sect. 2.2.2). The wavelengths below $400 \mathrm{~nm}$ account for $8 \%$ 
of the solar irradiance on top of the atmosphere, and wavelengths over $2100 \mathrm{~nm}$ account for $2 \%$ (Thuillier et al., 2003).

The shortwave albedo was obtained as a weighted sum of the spectral albedos, i.e., upward scattered fractions of incoming radiation $\left(f_{\lambda} \uparrow\right)$ :

albedo $=\sum_{\lambda=400}^{2100} w_{\lambda} \cdot f_{\lambda} \uparrow$

The canopy and total FAPAR (FAPAR CAN $_{\text {, FAPAR }}$ TOT) were obtained as weighted sums of canopy absorption $\left(a_{\lambda}^{\mathrm{C}}\right)$, and total absorption $\left(a_{\lambda}^{\mathrm{T}}\right)$ over the PAR region:

$$
\begin{aligned}
& \text { FAPAR }_{\mathrm{CAN}}=\sum_{\lambda=400}^{700} w_{\lambda} \cdot a_{\lambda}^{\mathrm{C}}, \\
& \text { FAPAR }_{\mathrm{TOT}}=\sum_{\lambda=400}^{700} w_{\lambda} \cdot a_{\lambda}^{\mathrm{T}} .
\end{aligned}
$$

The weights $\left(w_{\lambda}\right)$ were obtained from the solar irradiance spectrum. Solar irradiance values $\left(\mathrm{W} \mathrm{m}^{-2}\right)$ were scaled by dividing them with the total solar irradiance within the spectral region used (i.e., 400-2100 or 400-700 nm). The weights were thus unitless and summed up to unity. The canopy and total absorptions needed for FAPAR determination were obtained using upward scattered $\left(f_{\lambda} \uparrow\right)$ and downwelling $\left(f_{\lambda} \downarrow\right)$ fractions of incoming radiation, and the reflectance factor of the forest floor $\left(\rho_{\mathrm{G}}\right)$ as follows:

$a_{\lambda}^{\mathrm{C}}=1-f_{\lambda} \uparrow-f_{\lambda} \downarrow+\rho_{\lambda}^{\mathrm{G}} \cdot f_{\lambda} \downarrow$,

$a_{\lambda}^{\mathrm{T}}=1-f_{\lambda} \uparrow$.

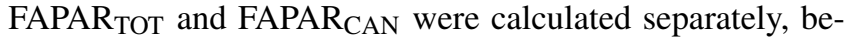
cause the former is a measure of total ecosystem productivity whereas the latter is more closely linked with timber production. Our FAPAR CAN $_{\text {and FAPAR }}$ TOT do not separate green biomass from woody or dead branches or from litter on the ground, and the values therefore represent upper limits of available solar energy for photosynthesis in tree canopies, and in the ecosystem as a whole. Green biomass could not be separated, because no measurements on fraction of branch area to leaf area were made in the study plots. The same applies to the cover of litter on the forest floor which was available for some of the field plots but not for all of them. It should also be noted that open soils are rarely seen in boreal forests where the floor is covered by (at least) green mosses.

The simulations were carried out assuming direct illumination only ("black-sky") and completely isotropic diffuse illumination ("white-sky"). Black sky albedo is not dependent on assumptions of atmospheric scattering properties, and is commonly used as an input in climate modeling (Schaaf et al., 2009). The white-sky case was included in order to represent a realistic diffuse illumination scenario, i.e., cloudy days. The black-sky albedo and FAPAR were simulated for five SZAs typical for the study areas: 40, 50, 60, 70, and $80^{\circ}$.
We use terms "small SZA" and "large SZA" to refer to SZAs of $40-50$ and $70-80^{\circ}$, respectively.

In both black- and white-sky simulations, we used a topof-atmosphere irradiance spectrum (Thuillier et al., 2003) for weighting, because the focus was on analyzing the effects of forest structure, and we wanted to avoid introducing any differences between the study areas due to imperfect parameterization of the atmosphere. However, in order to demonstrate what would be the effect of atmosphere on our results, we applied a simple solar spectral model (Bird and Riordan, 1986) for generating direct and diffuse components of atground solar irradiance spectra. The direct and diffuse components were then used to weight the spectral fluxes $\left(f_{\lambda} \uparrow\right.$, $\left.f_{\lambda} \downarrow\right)$ simulated under direct and diffuse illumination, respectively. The simulated actual (blue-) sky albedo and FAPAR were highly correlated $(r>=0.98)$ with black-sky ones, but blue-sky albedo was higher than black-sky albedo when SZA was 70 or $80^{\circ}$. This is because scattering in the atmosphere increases as function of SZA. The atmosphere scatters visible wavelengths more effectively than infrared wavelengths, shifting the irradiance distribution of incoming solar radiation towards longer wavelengths in which vegetation is more reflective. Because of high correlation between black- and blue-sky results, we conclude that inclusion of atmosphere in the calculations would not significantly change our conclusions, although would increase the simulated albedo values at large SZAs.

\subsubsection{Model parameters}

Tree crowns are represented in the FRT model by geometric primitives (cylinders, cones, ellipsoids, or combinations of them). The foliage within a crown is assumed to be homogeneously distributed. The area volume density (area per unit crown volume) of the foliage depends on the crown dimensions and on the foliage area per tree. Several tree classes can be defined to represent different tree species or size classes. We used one class for each tree species but did not model size variation within-species. In theory, a forest with trees of very different sizes would have a higher canopy surface roughness, which could in turn lead to somewhat lower reflectance (albedo) values (Davidson and Wang, 2004). There were no field measurements made on tree size distribution in our data from Finland, and we wanted to maintain the same calculation procedure for both study areas, in order not to introduce any differences due to data-processing steps. Because the maximum number of species was seven in the Alaskan data, there was a maximum of seven tree classes per plot. We assumed ellipsoid crown shape. The effect of crown shape on simulated forest bidirectional reflectance distribution function (BRDF) was quantified in Rautiainen et al. (2004), who showed that increasing the crown volume may either increase or decrease the simulated reflectance values, depending on canopy closure. An ellipsoid shape has been shown to estimate crown volume accurately (Rautiainen et al., 2008) and 
was therefore used in our study. Crown length was obtained from field measurements, and the crown radius was modeled using species-specific allometric equations that require stem diameter as an independent variable (Jakobsons, 1970; Bragg, 2001). Leaf dry biomass was estimated with speciesspecific biomass equations (Repola, 2008, 2009; Yarie et al., 2007) and converted into hemi-surface, i.e., half of total leaf area, using leaf mass per area (LMA) values from literature (Table 3). The performance of a wide range of crown radius and foliage mass models in forming the input of FRT has been reported by Lang et al. (2007). The models used in our study were chosen based on geographical proximity to our study areas, and also on model availability, particularly for the Alaskan species for which there existed a limited number of models. A slightly regular spatial distribution pattern of trees was assumed, i.e., a value of 1.2 for the tree distribution parameter (a value of 1 indicates Poisson distribution, Nilson, 1999). Other structural parameters needed in FRT simulations are presented in Table 3.

Optical properties (i.e., reflectance and transmittance of the leaves and needles) were obtained from laboratory spectrometer measurements. The data for Finnish species were from Hyytiälä, Finland (Lukeš et al., 2013b). Spectra of birch were used for all broadleaved species. The data for Alaskan species were from Superior National Forest, Minnesota, USA (Hall et al., 1996). Data for all species could not be found separately, and therefore spectra of black spruce were used for both black and white spruce, spectra of paper birch (Betula papyrifera Marsh.) were used for both birch species, and spectra of quaking aspen were used for both quaking aspen and for the black cottonwood/balsam poplar group. Reflectance spectra of black and white spruce needles have been found to be similar at least in the visible and near-infrared wavelengths (Richardson et al., 2003). In our data, the spectra of coniferous species did not differ notably from each other (Fig. 3a). The same applied to broadleaved species. Bark spectra for spruces and Populus sp. in Alaska were obtained from Hall et al. (1996), and for Scots pine and Norway spruce in Finland from Lang et al. (2002) (Fig. 3b). Spectra of birch from Lang et al. (2002) were used for birches in Alaska and for broadleaved species in Finland.

We used the annual shoot as a basic scattering element for conifers, similarly as in Lukeš et al. (2013a). This accounts for the multiple scattering within the shoot which results in the shoot albedo being lower than needle albedo. Shoot reflectance and transmittance spectra were obtained by upscaling the needle single scattering albedo to shoot albedo (Rautiainen et al., 2012), assuming that the reflectance-totransmittance ratio of a shoot is equal to that of a needle. BiLambertian scattering properties of the scattering elements (leaves or shoots) were assumed.

Optical properties of the forest floor (i.e., reflectance factors at nadir view) were obtained from field spectrometer measurements. The data were collected from Poker Flat Research Range Black Spruce Forest, Alaska (measurements described in Yang et al., 2014), and from Hyytiälä, Finland (using similar methodology as in Rautiainen et al., 2011). Separate spectra for each forest floor type was used (Fig. 3c), because characteristics of the forest floor may influence the forest reflectance and therefore also albedo (Rautiainen et al., 2007). Forest floor composition was assumed to be independent of overstory density. Taking into account this dependence would have required quantitative data on forest floor composition and spectral data on all of the forest floor components, which were not available. Analysis of a subset of plots that had measurements of vegetation cover in the forest floor revealed that the cover of green vegetation in the forest floor was only weakly correlated with the canopy closure of the overstory (Alaska $r=-0.27$; Hyytiälä (Finland) $r=-0.33)$.

\subsection{Data analyses}

\subsubsection{Albedo, FAPAR, and forest structure}

We analyzed albedo and FAPAR (FAPAR CAN $_{\text {FAPAR }}$ TOT) against each other, and against the forest variables. The analyses were performed separately for Alaskan and Finnish data, and repeated for all simulated solar illumination conditions. Because of the strong emphasis on forest management, the main focus of the analysis was on tree species and tree height which are usually measured as part of forest inventories. In addition, we analyzed albedo and FAPAR against effective leaf area index $\left(\mathrm{LAI}_{\mathrm{eff}}\right)$ and above-ground biomass (AGB). LAI $_{\text {eff }}$ is calculated by FRT, and corresponds to the LAI of a horizontally homogeneous, optically turbid canopy that has exactly the same transmittance (gap probability) as the canopy under examination. AGB was calculated with individual-tree allometric equations (Repola, 2008, 2009; Yarie et al., 2007), similarly as the foliage biomass.

In the next phase, all simulations were repeated assuming black soil (i.e., a totally absorbing background), in order to better explain the dependencies of albedo on tree height and illumination conditions as well as to explain the differences of albedo between Alaskan and Finnish forests. The albedo obtained in black-soil simulation represents the plain canopy albedo without the contribution of forest floor vegetation. We refer to this as "canopy contribution". Correspondingly, the contribution of forest floor can be calculated by subtracting the canopy contribution from the albedo obtained when assuming a vegetated forest floor. We refer to this as "forest floor contribution". Canopy and forest floor contributions can be expressed as absolute values or relative values which sum up to $100 \%$. For comparison with the results regarding albedo, the forest floor contribution to total ecosystem FAPAR was also calculated, by subtracting FAPAR $_{\text {CAN }}$ from FAPAR $_{\text {TOT. }}$.

We report the relationships of albedo and FAPAR against forest structure in Sect. 3.1. Results of these experiments are 
Table 3. Structural input parameters used in the FRT model simulations.

\begin{tabular}{lrrrr}
\hline & $\begin{array}{r}\text { Leaf mass per } \\
\text { area }\left(\mathrm{g} \mathrm{m}^{-2}\right)^{1}\end{array}$ & $\begin{array}{r}\text { Shoot shading } \\
\text { coefficient }^{2}\end{array}$ & $\begin{array}{r}\text { Shoot length } \\
(\mathrm{m})^{3}\end{array}$ & $\begin{array}{r}\text { Branch area to } \\
\text { leaf area ratio }\end{array}$ \\
\hline Alaska & & & & \\
\hline Black spruce & 187 & 0.50 & 0.05 & 0.18 \\
White spruce & 182 & 0.50 & 0.05 & 0.18 \\
Quaking aspen & 57 & 1 & 0.40 & 0.15 \\
Balsam poplar & 86 & 1 & 0.40 & 0.15 \\
Birches & 54 & 1 & 0.40 & 0.15 \\
\hline Finland & & & & \\
\hline Scots pine & 158 & 0.59 & 0.10 & 0.18 \\
Norway spruce & 200 & 0.64 & 0.05 & 0.18 \\
Broadleaved & 57 & 1 & 0.40 & 0.15 \\
\hline
\end{tabular}

${ }^{1}$ Black spruce and white spruce (Reich et al., 1999), quaking aspen and birches in Alaska (Bond-Lamberty et al., 2002), balsam poplar (Sigurdsson et al., 2001), Scots pine (Palmroth and Hari, 2001), Norway spruce (Stenberg et al., 1999), broadleaved species in Finland (values of birch from Kull and Niinemets, 1993).

2 Projected to total needle area in a shoot. Measures the effective leaf area, taking into account the self-shading of needles in a shoot. Black spruce and white spruce (Thérézien et al., 2007), Scots pine (Smolander et al., 1994), Norway spruce (Stenberg et al., 1995). ${ }^{3}$ Same values as used by Lukeš et al. (2013a).
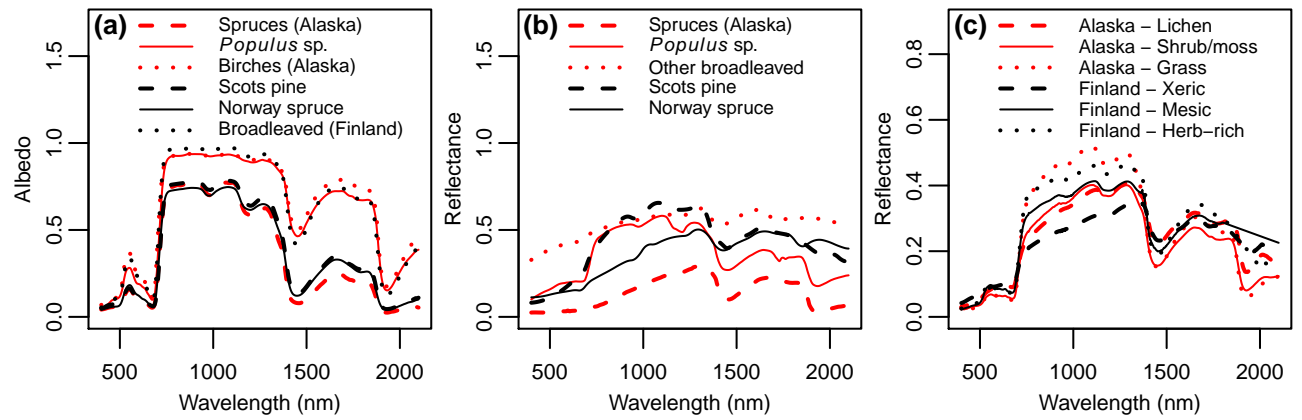

Figure 3. Spectra of vegetation elements used in the simulations: (a) leaves/shoots, (b) bark, and (c) forest floor. The values for leaf and shoot are single scattering albedos (reflectance + transmittance), and the values for bark and forest floor are reflectance factors.

needed for understanding the relations between albedo and FAPAR, which we report in Sect. 3.2.

\subsubsection{Relative importance of density and tree species}

To examine the relative importance of density and species composition, we analyzed albedo and FAPAR $\mathrm{RAN}_{\mathrm{N}}$ against basal area and the proportion of broadleaved trees. The analyses were performed separately for Alaska and Finland, and repeated for all simulated solar illumination conditions. We excluded all plots with tree height less than $10 \mathrm{~m}$ from the analyses in order to evaluate the effect of basal area independent of tree height. This was done based on the following reasoning. Basal area was correlated with tree height when studying all plots ( $r=0.61$ (Alaska), $r=0.64$ (Finland)). Preliminary analysis was performed by successively removing plots with the smallest trees and checking each time the correlation between height and basal area. The correlation was reduced until a height threshold of $10 \mathrm{~m}(r=0.40$
(Alaska), $r=0.34$ (Finland)) (cf. Fig. 2). Therefore, the $10 \mathrm{~m}$ threshold was used to exclude the smallest trees from our analyses. Analysis of albedo and FAPAR against basal area in this restricted set of plots gives an approximation of how thinnings would affect albedo and FAPAR ${ }_{\text {CAN }}$, although in reality thinning a stand affects not only the basal area but also the spatial pattern and size distribution of trees.

Mean and standard deviation (SD) of albedo and FAPAR $_{\text {CAN }}$ in conifer-dominated forests were calculated for 10 equally spaced classes with respect to basal area. The center of the lowest class corresponded to the 5th and that of the highest class to the 95th percentile of basal area in the data. To examine the effect of broadleaved proportion, mean and SD of albedo and FAPAR $\mathrm{CAN}_{\mathrm{N}}$ were calculated for 10 equally spaced classes with respect to proportion of broadleaved trees, i.e., the broadleaved proportions ranging from $0-10$ to $90-100 \%$. The analysis was repeated for sparse (basal area percentiles from 0th to 30th) and dense forest (basal area percentiles from 70th to 100th). We hypothesized 
that the proportion of broadleaved trees would have a smaller effect on albedo in sparse than in dense forest, because the forest floor has a more significant role in the sparse canopies. Results regarding the analysis of basal area and proportion broadleaved trees are reported in Sect. 3.3.

\section{Results}

\subsection{Albedo, FAPAR, and forest structure}

Mean albedo of study plots in Alaska (0.141-0.184) was higher than in Finland (0.136-0.171). In general, the albedo of broadleaved species was $42-130 \%$ higher than that of coniferous (Table 4). However, albedo varied greatly even among coniferous species: in Alaska, the albedo of black spruce was $19-33 \%$ higher than that of white spruce, and in Finland, the albedo of Scots pine forests was 20-31\% higher than that of Norway spruce. Overall, the mean albedo of coniferous species was $28-32 \%$ higher in Finland (0.1310.161) than in Alaska (0.102-0.122). The mean albedos of broadleaved species in Alaska did not differ significantly from each other ( $p>0.05$ in ANOVA), except in the whitesky case. Therefore the broadleaved species were treated as one group thereafter. Increasing the SZA increased the blacksky albedos of all species (Table 4).

The forest canopies in Alaska absorbed more PAR than in Finland: mean FAPAR CAN $_{\text {in Alaska was } 0.71-0.92 \text { and }}$ in Finland 0.63-0.89. At the smallest SZA $\left(40^{\circ}\right)$ in blacksky simulations, FAPAR CAN $_{\text {was }}$ highest for broadleaved species in Alaska, followed by Norway spruce in Finland, white spruce in Alaska, and broadleaved in Finland (Table 4). Scots pine in Finland and black spruce in Alaska had lowest FAPAR CAN $_{\text {among the species. The mean FAPAR }}$ CAN of broadleaved species in Alaska did not differ significantly from each other in any of the simulated illumination conditions ( $p>0.05$ in ANOVA). Increasing the SZA

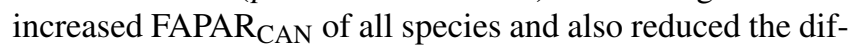
ferences between species. The relative increase was smaller for broadleaved than for coniferous species. Therefore, the order of species in FAPAR $\mathrm{CAN}_{\mathrm{N}}$ was different at small and large SZAs (Table 4). FAPAR TOT, an approximation of total ecosystem productivity, ranged from 0.93 to 0.98 and did not depend strongly on direction of illumination. FAPAR ${ }_{\mathrm{TOT}}$ of coniferous forests was higher than that of broadleaved but the differences were not large in relative terms because FAPAR ${ }_{\text {TOT }}$ was consistently high.

White-sky albedo corresponded best with black-sky albedo observed at SZA of $60^{\circ}(r=0.97, \mathrm{RMSE}=0.011$, mean difference $=-0.001)$. It correlated strongly also with black-sky albedos observed at other SZAs $(r \geq 0.93)$. White-sky FAPAR $_{\text {CAN }}$ corresponded best with blacksky FAPAR $_{\text {CAN }}$ observed at SZA of $40^{\circ}(r=1.00$, RMSE $=0.04$, mean difference $=0.03$ ) and very closely also with those observed at SZAs of 50 and $60^{\circ}$. On the other
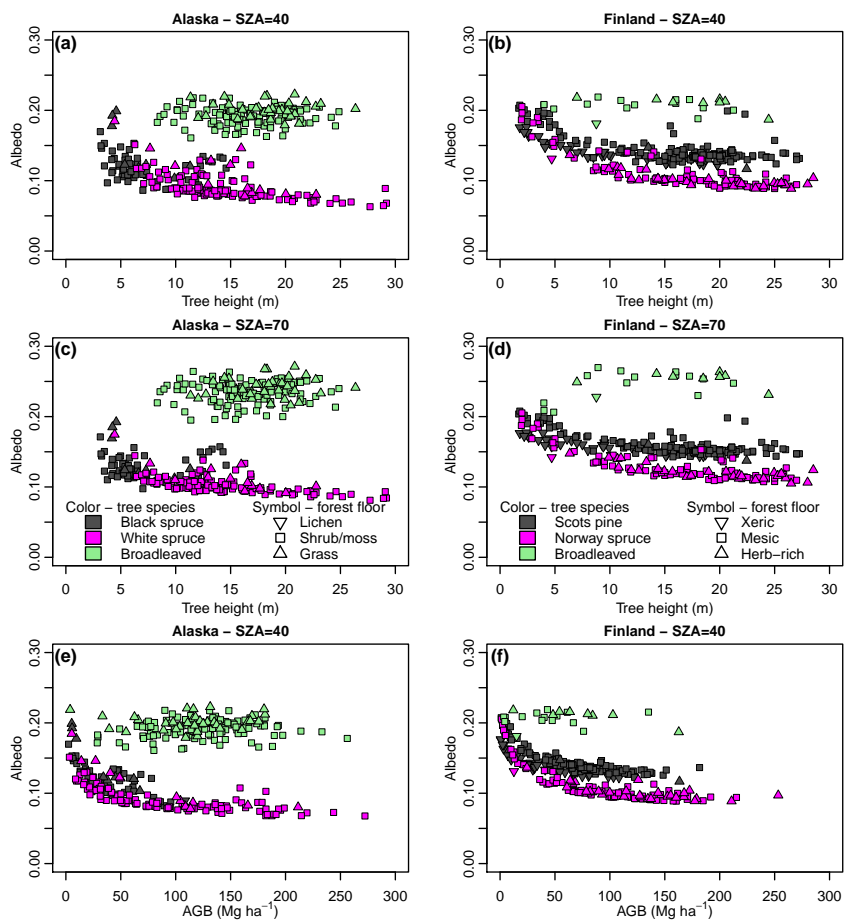

Figure 4. Forest black-sky albedo as a function of tree height (ad) and AGB (e-f). Relations to tree height are shown for two SZAs, $40^{\circ}(\mathbf{a}-\mathbf{b})$ and $70^{\circ}(\mathbf{c}-\mathbf{d})$, representing solar noon at midsummer and the annual average in the study regions. Left hand column shows the results for the Alaskan data, and right hand column for the Finnish data. The figures show only monospecific plots, i.e., plots in which the basal area proportion of one of the species exceeded $80 \%$.

hand, it deviated notably from the black-sky FAPAR CAN $_{\text {ob- }}$ served at SZAs of 70 and $80^{\circ}$. Because white-sky albedo and FAPAR were highly correlated with their black-sky counterparts observed at small to moderate SZAs, we report the results hereafter for black-sky conditions only, except for contribution of forest floor (Table 5), which is also presented for white-sky cases in order to maintain comparability with results presented in Table 4.

Albedo decreased with increasing tree height in coniferous forests (Fig. 4). The decrease was most rapid at small tree heights and saturated after the height reached approximately $10 \mathrm{~m}$. When SZA increased, the difference in albedo between short and tall forests became smaller (compare Fig. 4a, b to $\mathrm{c}, \mathrm{d}$ ). The albedo of broadleaved forests was similar for all tree heights at the smallest SZA $\left(40^{\circ}\right)$. At large SZAs, however, there was an initial rapid increase in albedo for broadleaved forests with small trees (Fig. 4d), after which the albedo remained stable. AGB was correlated with tree height $(r=0.72-0.78)$ and the albedo responded to AGB with a similar saturating trend as in the case of tree height (Fig. 4e, f).

FAPAR $_{\text {CAN }}$ initially increased with increasing tree height, but saturated at large tree heights (Fig. 5). The saturation was 


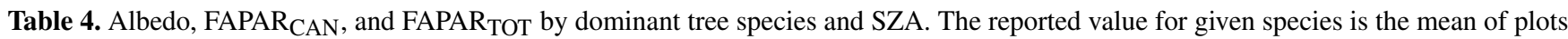
in which the basal area proportion of that species exceeded $80 \%$. The number of plots and mean forest variables for each species are reported in Table 1.

\begin{tabular}{lcccccc}
\hline \multirow{2}{*}{ Tree species } & \multicolumn{5}{c}{ Black-sky (SZA) } & \multirow{2}{*}{ White-sky } \\
\cline { 2 - 6 } & $40^{\circ}$ & $50^{\circ}$ & $60^{\circ}$ & $70^{\circ}$ & $80^{\circ}$ & \\
\hline Albedo & & & & & & \\
\hline Black spruce & 0.121 & 0.122 & 0.124 & 0.128 & 0.137 & 0.124 \\
White spruce & 0.091 & 0.094 & 0.097 & 0.103 & 0.114 & 0.104 \\
Broadleaved (Alaska) & 0.194 & 0.204 & 0.218 & 0.236 & 0.262 & 0.205 \\
Scots pine & 0.144 & 0.147 & 0.152 & 0.159 & 0.172 & 0.151 \\
Norway spruce & 0.110 & 0.114 & 0.120 & 0.128 & 0.141 & 0.126 \\
Broadleaved (Finland) & 0.207 & 0.218 & 0.231 & 0.248 & 0.273 & 0.224 \\
\hline FAPAR CAN & & & & & & \\
\hline Black spruce & 0.47 & 0.53 & 0.61 & 0.72 & 0.86 & 0.53 \\
White spruce & 0.72 & 0.77 & 0.84 & 0.90 & 0.95 & 0.74 \\
Broadleaved (Alaska) & 0.78 & 0.82 & 0.86 & 0.89 & 0.91 & 0.80 \\
Scots pine & 0.50 & 0.57 & 0.65 & 0.75 & 0.86 & 0.55 \\
Norway spruce & 0.73 & 0.79 & 0.84 & 0.89 & 0.92 & 0.74 \\
Broadleaved (Finland) & 0.60 & 0.65 & 0.71 & 0.76 & 0.81 & 0.62 \\
\hline FAPAR TOT & & & & & & \\
\hline Black spruce & 0.97 & 0.97 & 0.97 & 0.97 & 0.97 & 0.97 \\
White spruce & 0.98 & 0.98 & 0.98 & 0.98 & 0.98 & 0.98 \\
Broadleaved (Alaska) & 0.95 & 0.95 & 0.94 & 0.94 & 0.93 & 0.95 \\
Scots pine & 0.97 & 0.97 & 0.97 & 0.97 & 0.96 & 0.96 \\
Norway spruce & 0.97 & 0.97 & 0.97 & 0.97 & 0.97 & 0.97 \\
Broadleaved (Finland) & 0.95 & 0.95 & 0.94 & 0.94 & 0.93 & 0.94 \\
\hline & & & & & & \\
\hline
\end{tabular}

reached earlier and the maximum level of FAPAR $\mathrm{CAN}_{\mathrm{N}}$ was higher at large SZAs. Similar saturating trends and SZA dependencies were also observed against AGB although there was less variation in the $y$ direction (Fig. 5e, f). FAPAR ${ }_{\text {TOT }}$ increased as a function of tree height in coniferous forests, and was stable in broadleaved forests (Fig. 6). However, the variation in FAPAR $\mathrm{TOT}_{\mathrm{T}}$ with tree height was small (values ranging from 0.93 to 0.98 ).

The average contribution of forest floor to total forest albedo depended on tree species and ranged from 4 to $53 \%$ (Table 5). It was largest at small SZAs and for tree species

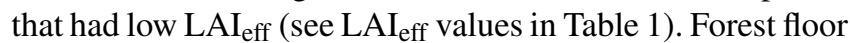
contribution decreased as a function of tree height (Fig. 7). The relation was even tighter when the forest floor contribution was analyzed against $\mathrm{LAI}_{\mathrm{eff}}$ (not shown). This is logical because $\mathrm{LAI}_{\mathrm{eff}}$ is more directly linked with canopy transmittance than is tree height. Increasing the SZA increased the canopy contribution in all plots. This caused the albedo to increase as a function of SZA. Only a few sparse canopies (low $\mathrm{LAI}_{\text {eff }}$ ) were an exception. In these plots, an increase in SZA reduced the forest floor contribution more than it increased the canopy contribution. Results regarding contribution of forest floor to total ecosystem FAPAR were similar to those observed for albedo, i.e., there were differences between tree species and decreasing trends with increasing SZA (Table 5).

The differences in albedos between coniferous species (i.e., black spruce vs. white spruce and Scots pine vs. Norway spruce) were almost non-existent when comparing albedos obtained in black-soil simulations (Table 5). This indicates that at least some of the differences in albedos between coniferous species are explained by the varying forest floor contribution between species. However, the differences in albedos between coniferous forests of Finland and Alaska remained, indicating that factors other than forest floor influenced the species differences between the study areas.

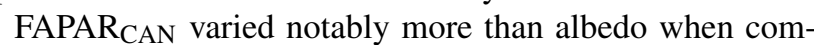
paring forests of the same height, particularly at small SZAs (Figs. 4, 5). This can be explained by the link between FAPAR CAN $_{\text {and canopy interception. Interception was }}$ tightly related with $\mathrm{LAI}_{\text {eff }}$ (not shown), and it determined FAPAR $_{\text {CAN }}$ almost directly, because the foliage absorbed strongly at PAR wavelengths (Fig. 3a) and therefore the multiple scattering was negligible. $\mathrm{LAI}_{\mathrm{eff}}$, in turn, varied considerably between forests of the same height. The outliers

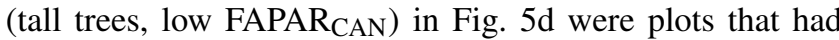
only few trees and therefore very low $\mathrm{LAI}_{\mathrm{eff}}$. Similarly, Scots

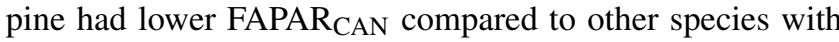



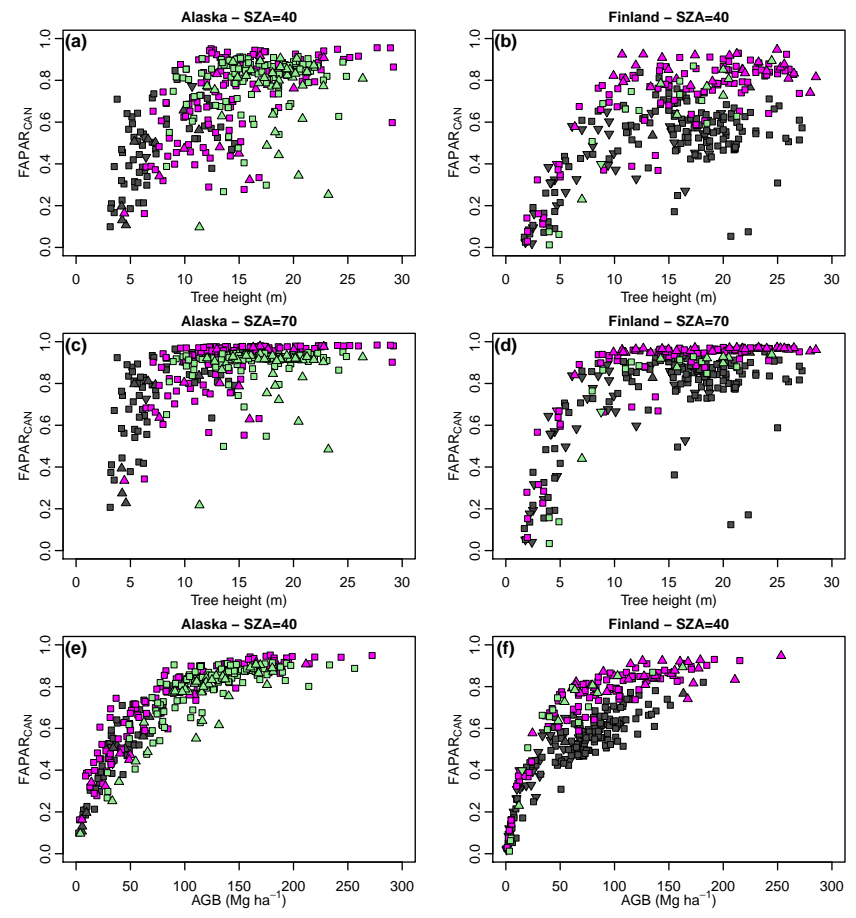

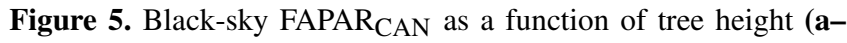
d) and AGB (e-f). Relations to tree height are shown for two SZAs, $40^{\circ}(\mathbf{a}-\mathbf{b})$ and $70^{\circ}(\mathbf{c}-\mathbf{d})$, representing solar noon at midsummer and the annual average in the study regions. Left hand column shows the results for the Alaskan data, and right hand column for the Finnish data. The figures show only monospecific plots, i.e., plots in which the basal area proportion of one of the species exceeded $80 \%$. For explanation of the symbols, see legend in Fig. 4.
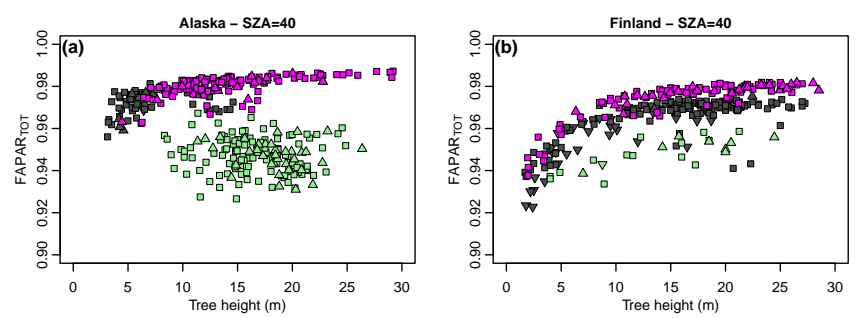

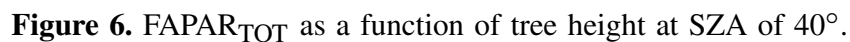
The figures show only monospecific plots, i.e., plots in which the basal area proportion of one of the species exceeded $80 \%$. For explanation of the symbols, see legend in Fig. 4.

the same height (Fig. 5d). Further examination revealed that Scots pine had short crowns and therefore low $\mathrm{LAI}_{\mathrm{eff}}$, although the leaf area per unit crown volume did not differ from the other coniferous species. The strong link between FAPAR ${ }_{\text {CAN }}$ and $\mathrm{LAI}_{\text {eff }}$ also explained the observed species

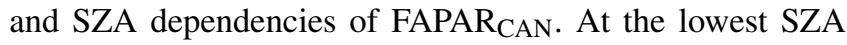
$\left(40^{\circ}\right)$ the species-specific FAPAR CAN $_{\text {(Table } 4) \text { was strongly }}$ correlated with species-specific $\mathrm{LAI}_{\text {eff }}$ (Table 1) $(r=0.93)$. At large SZAs the canopy interception approached $100 \%$ at
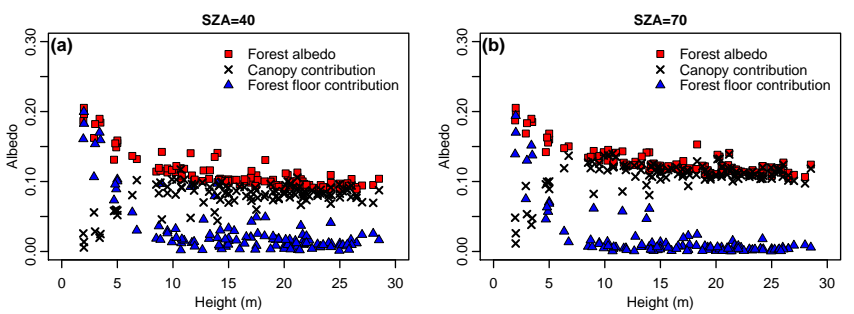

Figure 7. Canopy and forest floor contributions to forest black-sky albedo as function of tree height. Canopy contribution was obtained by assuming black soil in the simulation. Forest floor contribution was obtained by subtracting the canopy contribution from the total forest albedo. The data shown are from Norway spruce dominated forests in Finland.

almost all $\mathrm{LAI}_{\text {eff }}$ values (cf. Fig. 5c, d) and FAPAR $\mathrm{CAN}_{\text {was }}$ therefore mainly determined by the absorption of the foliage at PAR wavelengths. Leaves of broadleaved trees absorbed less than conifer needles, which explains why FAPAR CAN $_{\text {of }}$ broadleaved species did not increase as rapidly as a function

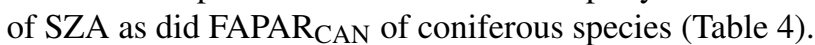

\subsection{Relation of albedo to FAPAR}

FAPAR $_{\text {CAN }}$ was negatively correlated with albedo in conifer dominated forests (Fig. 8). The correlation was strongest at the smallest SZA $(r=-0.91, r=-0.90)$ and weakest at the largest SZA ( $r=-0.63, r=-0.59)$. When including mixed plots and the plots dominated by broadleaved trees, correlation of FAPAR CAN $_{\text {to albedo varied from almost non-existent }}$ in Alaska ( $r$ ranging from -0.17 to 0.07 ) to moderate in Finland ( $r$ ranging from -0.62 to -0.30 ). The higher correlation in Finland can be explained by the small number of broadleaf-dominated forests in our data from Finland. In addition to the proportion of broadleaved trees, variation in forest floor characteristics influenced the albedo-FAPAR $\mathrm{CAN}_{\mathrm{C}}$ relations by altering the albedo values (Fig. 8). The effect of forest floor was seen in relatively sparse canopies only. For example, at SZA of $40^{\circ}$ the effect of forest floor on albedo started to show at FAPAR $\mathrm{RAN}_{\mathrm{CAN}}$ values below 0.5 (Fig. 8). Taking into account that FAPAR ${ }_{\text {CAN }}$ was tightly related to $\mathrm{LAI}_{\text {eff }}$, this value corresponds to an $\mathrm{LAI}_{\mathrm{eff}}$ of approximately 1 . FAPAR ${ }_{\mathrm{TOT}}$ was strongly and negatively correlated with albedo ( $r$ ranging from -0.97 to -0.88 ). The only plots that deviated from this otherwise strong relation were those Scots pine plots that had low FAPAR TOT $_{\text {and }}$ xeric forest floor.

\subsection{Relative importance of density and tree species}

The variation in density of forests was larger in Alaska than in Finland; the 5th and 95th percentiles of basal area were 8 and $43 \mathrm{~m}^{2} \mathrm{ha}^{-1}$ in Alaska, and 10 and $34 \mathrm{~m}^{2} \mathrm{ha}^{-1}$ in Finland. In both study areas, decrease in basal area resulted in higher

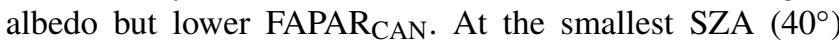




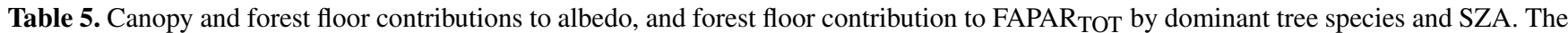
reported value for given species is the mean of plots in which the basal area proportion of that species exceeded $80 \%$. Note that the values are directly comparable to the species-specific forest albedos and FAPAR values reported in Table 4, i.e., exactly the same plots were used to calculate the average values in both tables.

\begin{tabular}{lcrrrrr}
\hline Tree species & \multicolumn{7}{c}{ Black-sky (SZA) } \\
& $40^{\circ}$ & $50^{\circ}$ & $60^{\circ}$ & $70^{\circ}$ & $80^{\circ}$ & White-sky \\
\hline Forest albedo when assuming black soil & & & & \\
\hline Black spruce & 0.053 & 0.059 & 0.069 & 0.084 & 0.108 & 0.066 \\
White spruce & 0.062 & 0.068 & 0.076 & 0.087 & 0.104 & 0.081 \\
Broadleaved (Alaska) & 0.169 & 0.182 & 0.199 & 0.221 & 0.251 & 0.186 \\
Scots pine & 0.075 & 0.084 & 0.096 & 0.114 & 0.140 & 0.094 \\
Norway spruce & 0.079 & 0.087 & 0.097 & 0.109 & 0.128 & 0.102 \\
Broadleaved (Finland) & 0.140 & 0.155 & 0.173 & 0.197 & 0.231 & 0.165 \\
\hline Contribution of forest floor to total forest albedo, \% & & & \\
\hline Black spruce & 52.9 & 48.0 & 41.4 & 32.4 & 20.2 & 46.8 \\
White spruce & 27.9 & 23.7 & 19.0 & 13.7 & 8.0 & 22.1 \\
Broadleaved (Alaska) & 12.9 & 10.9 & 8.7 & 6.5 & 4.3 & 9.3 \\
Scots pine & 45.6 & 40.6 & 34.5 & 26.8 & 17.9 & 37.7 \\
Norway spruce & 23.5 & 19.7 & 15.8 & 11.9 & 8.0 & 19.0 \\
Broadleaved (Finland) & 32.7 & 29.5 & 25.9 & 21.9 & 17.1 & 26.3 \\
\hline Contribution of forest floor to FAPAR TOT, \% & & & \\
\hline Black spruce & 50.1 & 44.1 & 36.0 & 25.1 & 11.1 & 45.7 \\
White spruce & 26.4 & 20.6 & 14.5 & 8.3 & 2.6 & 24.3 \\
Broadleaved (Alaska) & 16.9 & 12.5 & 8.3 & 4.6 & 2.0 & 15.9 \\
Scots pine & 46.3 & 39.8 & 31.7 & 21.5 & 10.5 & 42.8 \\
Norway spruce & 24.4 & 18.7 & 13.2 & 8.3 & 4.4 & 23.3 \\
Broadleaved (Finland) & 34.7 & 29.3 & 23.5 & 17.7 & 12.4 & 34.3 \\
\hline
\end{tabular}

the decrease in basal area from its 95th to 5th percentile resulted in an increase in albedo of $36 \%$ in Alaska and of $21 \%$ in Finland (Fig. 9). Correspondingly, FAPAR CAN $_{\text {decreased }}$ by $48 \%$ in Alaska and by $44 \%$ in Finland. When SZA increased, the response of FAPAR CAN $_{\text {to }}$ to basal area became weaker. For example, at SZA of $70^{\circ}$ the basal area could be reduced to approx. $20 \mathrm{~m}^{2} \mathrm{ha}^{-1}$ with equal relative changes in albedo and FAPAR ${ }_{\text {CAN }}$ (Fig. 9b). At the largest SZA $\left(80^{\circ}\right)$

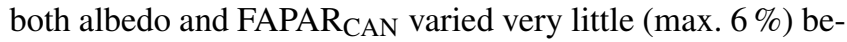
tween the 5th and 95th basal area percentiles. In other words, the effect of basal area depended strongly on SZA. However, the relative decrease of FAPAR ${ }_{\text {CAN }}$ with decreasing basal area was always larger than or equal to the relative increase in albedo.

Increasing the proportion of broadleaved trees increased the albedos considerably more than did reduction in basal area (Fig. 9c, d). The effect of broadleaved trees was slightly smaller in sparse than in dense forests. For example, at SZA of $40^{\circ}$, increasing the broadleaved proportion from $0-10$ to $90-100 \%$ resulted in relative increase in albedo of $130 \%$ (in Alaska) and $80 \%$ (in Finland) in forests with high basal area (i.e., basal area percentiles from 70th to 100th). In forests with low basal area (i.e., basal area percentiles from 0th to 30th) the corresponding figures were $112 \%$ (Alaska) and $71 \%$ (Finland). The smaller relative increase in Finland is explained by the higher albedo of Finnish coniferous forests, because the albedos of broadleaved species did not differ between Alaska and Finland. FAPAR ${ }_{\text {CAN }}$ was almost independent on the proportion of broadleaved trees, except for large SZAs where FAPAR ${ }_{\text {CAN }}$ tended to decrease slightly when broadleaved proportion increased (Fig. 9d). This is explained by the fact that at large SZAs FAPAR ${ }_{\text {CAN }}$ was mainly determined by the absorption of canopy elements, and the absorption was lower for broadleaved than for coniferous trees.

\section{Discussion}

Despite recent studies published on the relationships between albedo and boreal forest structure, and despite the widespread use of FAPAR to monitor vegetation productivity, the physical link between forest albedo and productivity has been poorly understood. To our knowledge, the relationship between these two quantities has not been quantified before for an extensive geographical area. Another gap in the discussion has been the role of latitude: solar paths vary across the biome, and therefore, need to be taken into 

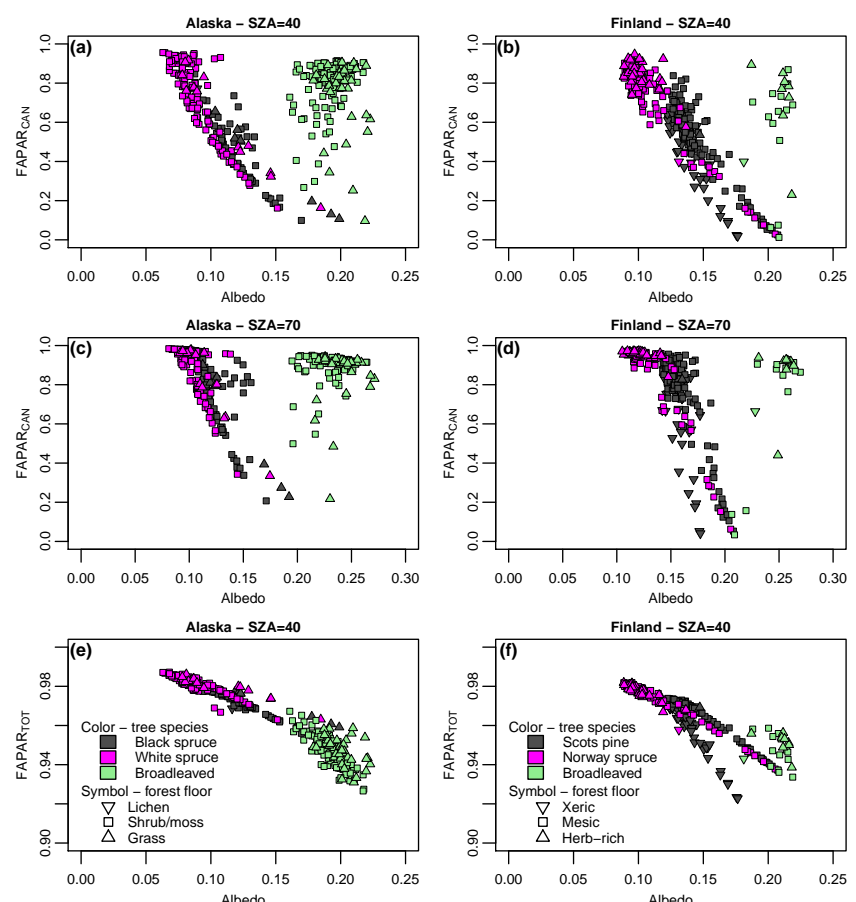

Figure 8. Relation of FAPAR to forest black-sky albedo by dominant tree species. The figures show only plots that were dominated by one species, i.e., in which the basal area proportion of one of the species exceeded $80 \%$. (a-d) FAPAR $\mathrm{CAN}_{\mathrm{N}}$ against albedo at two SZAs, $40^{\circ}$ and $70^{\circ}$, representing solar noon at midsummer and the annual average in the study regions; $(\mathbf{e}-\mathbf{f})$ FAPAR $_{\mathrm{TOT}}$ against albedo at SZA of $40^{\circ}$.

account before making any generalizations on how altering forest structure through silvicultural operations can be used to influence albedo (and furthermore, climate).

Our results show that albedo and FAPAR ${ }_{\text {CAN }}$ are tightly linked in boreal coniferous forests. The prerequisites for this are that there is only a limited proportion of broadleaved trees present in the forest and that the tree canopy is not very sparse (i.e., LAI is not very low). The explanation for the tight connection between albedo and FAPAR $\mathrm{CAN}_{\mathrm{C}}$ is that they respond with opposite trends to forest structural variables. However, the shapes of these trends depend on directional characteristics of the incoming solar radiation which was also reflected in the albedo vs. FAPAR ${ }_{\text {CAN }}$ relations. This underlines the importance of taking into account latitude and season (i.e., solar angle) when evaluating climate impacts of forests even within one biome. FAPAR ${ }_{\mathrm{TOT}}$ was also tightly linked with albedo. Because FAPAR ${ }_{\text {TOT }}$ equals one minus PAR albedo, this finding indicates that PAR albedo and shortwave albedo of vegetation are correlated. However, the overall variation in FAPAR $\mathrm{TOT}_{\mathrm{T}}$ was small in magnitude. Our results differ slightly from those observed by Lukeš et al. (2016), who compared satellite-based (MODIS) albedo and FAPAR in Finland and observed a much weaker (but still negative) correlation between these quantities. The spa-
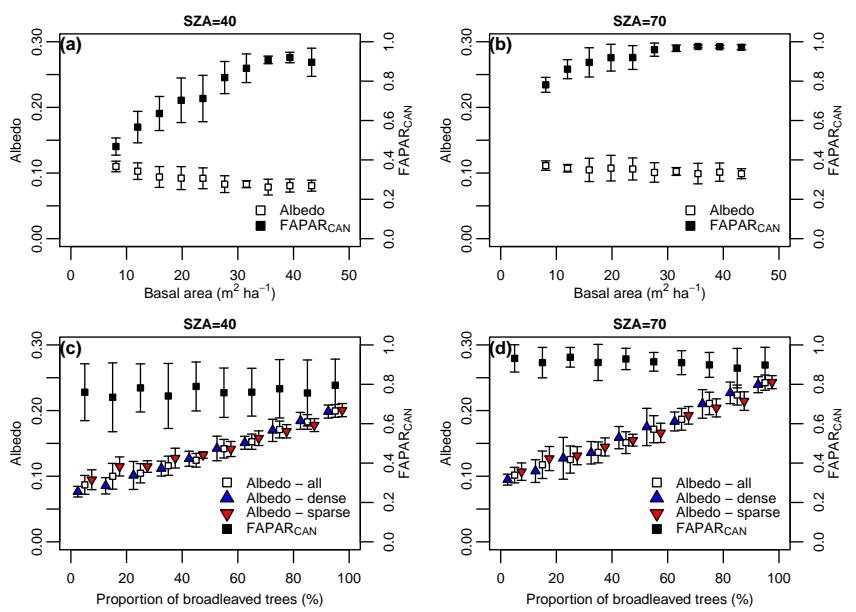

Figure 9. Effect of basal area (a-b) and proportion of broadleaved trees (c-d) on black-sky albedo and FAPAR ${ }_{\text {CAN }}$ at sun zenith angles of 40 and $70^{\circ}$ in Alaska. Points represent mean and whiskers the standard deviation in 10 equally spaced classes. Effect of broadleaved proportion on albedo is presented separately for dense (basal area $>31 \mathrm{~m}^{2} \mathrm{ha}^{-1}$ ) and sparse (basal area $<21 \mathrm{~m}^{2} \mathrm{ha}^{-1}$ ) forest. These limits correspond to 30th and 70th percentiles of basal area in Alaskan data. The points representing dense and sparse forest are shifted along the $x$ axis in order to make them visible.

tial resolution in their study $(1 \times 1 \mathrm{~km})$ was coarser than in our study, and the FAPAR definition differed: MODIS FAPAR is defined as PAR absorbed by green elements of vegetation canopy, both trees and understory included. In addition, Lukeš et al. (2016) did not separate coniferous and broadleaved trees, although this effect is likely minor since the proportion of broadleaved trees is on average low in Finland. Finally, simulation model used here, although parameterized by field observations, cannot capture all the variability in real forests, and on the other hand, satellite products are likely to include observation and modeling errors that increase the noise in the data.

The responses of albedo to tree species and forest structure were similar across the biome in Alaska and Finland. This corroborates findings in previous, local studies (Amiro et al., 2006; Bright et al., 2013; Lukeš et al., 2014; Kuusinen et al. 2014, 2016). Also the results regarding overall level of FAPAR ${ }_{\text {CAN }}$, and the dependence of FAPAR CAN $_{\text {on }}$ tree species, were similar to earlier studies (Roujean, 1999; Steinberg et al., 2006). However, as our study was based on extensive field data from two continents, drawing more general conclusions on how forest structure, albedo, and productivity are interconnected is now possible. In addition, to our knowledge only one study has previously evaluated the forest floor contribution to albedo (Kuusinen et al., 2015). We showed that forest floor vegetation (which is often in practical forestry, e.g., a proxy for site fertility type) can significantly contribute to forest albedo; its average contribution can be up to $50 \%$, varying between forests dominated by dif- 
ferent tree species. Similarly, the average contribution of forest floor to total ecosystem FAPAR can be up to or even over $50 \%$, as also reported previously by Ikawa et al. (2015) for an eddy-covariance study site in Alaska. In other words, even though forest floor vegetation often contributes only little to, for example, total forest biomass, it can have a significant role as a key driving factor of forest albedo and ecosystem productivity. Quantifying the variation in forest floor composition and optical properties across the boreal biome therefore constitutes an important research topic in the future. The important role of forest floor also means that any forest management that influences forest floor composition can significantly alter the biophysical climate effects of forests. For example, reindeer grazing has been suggested to reduce land surface albedo, because it reduces the cover of reindeer lichens that have higher albedo compared to mosses (Stoy et al., 2012).

The black-soil simulations that we conducted in order to quantify the contribution of forest floor also explained why the albedo increased as a function of solar zenith angle. From previous simulation studies it is known that when the sun approaches the horizon, the path length of radiation and therefore scattering from the canopy layer increase while the contribution of forest floor decreases (Kimes et al., 1987; Ni and Woodcock, 2000). The net effect is dependent on the density (gap fractions) of the canopy layer, and on the reflectance of the forest floor: if the canopy is sparse or clumped, or if the reflectance of the forest floor is high, it is likely that increasing the solar zenith angle reduces the forest floor contribution more than it increases the scattering from canopy. Our results generalize the findings of these previous studies that examined only few stands locally. It should be noted that our results apply only to summertime conditions. If the forest floor has high reflectance due to, e.g., snow cover, a decrease of albedo as a function of solar zenith angle is expected to be observed more often ( $\mathrm{Ni}$ and Woodcock, 2000).

We observed some interesting differences between Alaskan and Finnish data sets which deserve to be highlighted. Even though our field data do not represent a probability sample they are still a good representation of the forests in the study areas. The mean albedo was higher in Alaska than in Finland, because of the higher proportion of broadleaved species in Alaska. However, the coniferous forests in Alaska had lower albedos than those in Finland. There is some previous evidence to support this, because the lowest values reported by Amiro et al. (2006) for spruce forests in Alaska are lower than those reported by Kuusinen et al. (2014) for spruce in Finland. Because the difference also remained when assuming black soil, the reason is in the properties of the canopy layer. In particular, the low reflectance of bark in the Alaskan species (Fig. 3b) explains part of the difference.

Radiative transfer models offer a useful tool for assessing the radiation regime of forests, especially when the modeling approach can utilize readily available common forest inven- tory databases. Validating the simulated albedo and FAPAR values, however, is challenging. Even though international model intercomparison efforts such as RAMI (Widlowski et al., 2007) provide a rigorous set of reports on performance of radiative transfer models, the quality of available input data in each study where a radiative transfer model is applied is crucial. For example, the forest floor albedos that we calculated from the available reflectance spectra (Fig. 3) were clearly higher (0.18-0.23) than forest floor albedos measured in the field at other boreal sites (approx. 0.15 in Manninen and Riihelä, 2008, 2009; Kuusinen et al., 2014). If we had scaled our reflectance factors in order to obtain forest floor albedos of 0.15 , the simulated forest albedos would have decreased by $7-10 \%$. Furthermore, including the UV region in the simulations would have reduced the simulated albedos by up to $7 \%$, assuming that the optical properties of the canopy and forest floor are similar at UV than at $400 \mathrm{~nm}$. However, the lack of field-measured spectra for some of the Alaskan species is a limitation of our study and shows that there is an urgent need for a comprehensive spectral database of boreal tree species.

Our results regarding basal area give an idea of the magnitude of the effects that varying thinning regimes could have on forest albedo and productivity. The effect of thinnings on albedo have previously been estimated, mainly by in situ measurements at few selected sites (Kirschbaum et al., 2011; Kuusinen et al., 2014). In our study, reduction in the basal area reduced FAPAR CAN $_{\text {to }}$ to equal extent or more compared to how albedo changed. In contrast to basal area, the proportion of broadleaved trees had a notably larger effect on forest albedo while having only a negligible influence on forest productivity (FAPAR $\mathrm{CAN}_{\mathrm{CAN}}$ ). The relative importance of basal area and tree species nevertheless depends on the spectral properties of the tree species and forest floor. Based on our results, the effect of thinning (removal of basal area) on albedo and FAPAR depends on solar angle. Therefore, the influence of thinning on forest productivity differs between latitudes. Furthermore, because the basal area influenced albedo

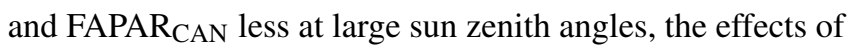
thinning integrated over entire rotation period may not be as large as they seem when studying them only at solar noon.

Global satellite products have provided us insight on coarse-scale trends of albedo in different biomes. However, their weakness is that even though we can establish correlations between changes in albedo and changes in land cover, we are still not able to identify and quantify the biophysical factors which cause the albedo of a forest area to change. In addition, a specific challenge in coupling forest management operations with changes in satellite-based albedo products is that the scale of these operations significantly differs in North America and northern Europe, and often does not directly correspond to the spatial resolution of current albedo products. With an understanding of the consequences of, for example, forest management practices on the albedo, best-practice recommendations for forest management in fu- 
ture climate mitigation policies will become more justified. By coupling extensive field inventory data sets and radiative transfer modeling, we showed that albedo and FAPAR CAN $_{1}$ are tightly linked in boreal coniferous forests at stand level. However, the relation is weaker if the forest has deciduous admixture, or if the canopies are sparse and at the same time the species composition (i.e., optical properties) of the forest floor varies. Because the shape of the relationship between

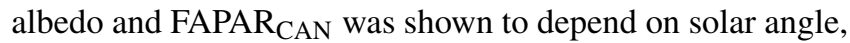
studies evaluating the climate effects of forest management strategies need to consider latitudinal effects due to varying solar paths. The comparisons between Alaska and Finland revealed that albedo and FAPAR $\mathrm{CAN}_{\mathrm{N}}$ differ between geographical regions because of the differences in forest structure. However, regardless of geographical region in the boreal zone, the potential of using thinning to increase forest albedo may be limited compared to the effect of favoring broadleaved species.

\section{Data availability}

Data from Co-operative Alaska Forest Inventory prior to 2009 are available at LTER Network Data Portal (Packee et al., 2010). Forest inventory data from Finland were mainly collected from private forests and are described in detail in Korhonen et al. (2011) and Majasalmi et al. (2015). Leaf and needle optical properties measured in Hyytiälä are reposited at SPECCHIO database (Lukeš et al., 2013b, http://www. specchio.ch/), and those measured in Superior National Forest are reposited at ORNL DAAC by NASA (Hall et al., 1996). Forest floor spectra are available as a Supplement of this article.

\section{The Supplement related to this article is available online at doi:10.5194/bg-13-6015-2016-supplement.}

Acknowledgements. This study was funded in part by the Academy of Finland projects BOREALITY and SATLASER, and by the Davis College of Agriculture, Natural Resources \& Design, West Virginia University, under the US Department of Agriculture (USDA) McIntire-Stennis Funds WVA00106. We thank Petr Lukeš and Matti Mõttus for advice on radiative transfer modeling, and Titta Majasalmi, Pekka Voipio, Jussi Peuhkurinen and Maria Villikka for organizing the measurements of field plots in Finland. We also thank the School of Natural Resources and Agricultural Sciences, University of Alaska, for the establishment and maintenance of the Co-operative Alaska Forest Inventory. The forest floor reflectances at Poker Flag Research Range were obtained under the JAMSTEC and IARC/UAF collaborative study (PI: Rikie Suzuki).

Edited by: S. Luyssaert

Reviewed by: two anonymous referees

\section{References}

Alkama, R. and Cescatti, A.: Biophysical climate impacts of recent changes in global forest cover, Science, 351, 600-604, 2016.

Amiro, B. D., Orchansky, A. L., Barr, A. G., Black, T. A., Chambers, S. D., Chapin, F. S., Goulden, M. L., Litvak, M., Liu, H. P., McCaughey, J. H., McMillan, A., and Randerson, J. T.: The effect of post-fire stand age on the boreal forest energy balance, Agr. For. Meteorol., 140, 41-50, 2006.

Bird, R. E. and Riordan, C.: Simple Solar Spectral Model for Direct and Diffuse Irradiance on Horizontal and Tilted Planes at the Earth's Surface for Cloudless Atmospheres, J. Clim. Appl. Meteorol., 25, 87-97, 1986.

Bond-Lamberty, B., Wang, C., Gower, S. T., and Norman, J.: Leaf area dynamics of a boreal black spruce fire chronosequence, Tree Physiol., 22, 993-1001, 2002.

Bragg, D. C.: A local basal area adjustment for crown width prediction, North. J. Appl. For., 18, 22-28, 2001.

Bright, R. M., Astrup, R., and Strømman, A. H.: Empirical models of monthly and annual albedo in managed boreal forests of interior Norway, Climatic Change, 120, 183-196, 2013.

Bright, R. M., Antón-Fernández, C., Astrup, R., Cherubini, F., Kvalevåg, M., and Strømman, A. H.: Climate change implications of shifting forest management strategy in a boreal forest ecosystem of Norway, Glob. Chang. Biol., 20, 607-621, 2014.

Cajander, A. K.: Forest types and their significance, Acta Forestalia Fennica, 56, 1-71, 1949.

Chasmer, L., Hopkinson, C., Treitz, P., McCaughey, H., Barr, A., and Black, A.: A lidar-based hierarchical approach for assessing MODIS fPAR, Remote Sens. Environ., 112, 4344-4357, 2008.

Davidson, A. and Wang, S.: The effects of sampling resolution on the surface albedos of dominant land cover types in the North American boreal region, Remote Sens. Environ., 93, 211-224, 2004.

Gobron, N. and Verstraete, M. M.: Assessment of the status of the development of the standards for the terrestrial essential climate variables. T10 Fraction of Absorbed Photosynthetically Active Radiation (FAPAR), V8, GTOS65, NRC, FAO, Rome, Italy, 124, 2009.

Hall, F. G., Huemmrich, K. F., Strebel, D. E., Goetz, S. J., Nickeson, J. E., and Woods, K. D.: SNF Leaf Optical Properties: Cary14, Superior National Forest Leaf Optical Properties: Cary-14, Data set, Available on-line from Oak Ridge National Laboratory Distributed Active Archive Center, Oak Ridge, Tennessee, USA, 1996. Based on Hall, F. G., Huemmrich, K. F., Strebel, D. E., Goetz, S. J., Nickeson, J. E., and Woods, K. D.: Biophysical, Morphological, Canopy Optical Property, and Productivity Data from the Superior National Forest, NASA Technical Memorandum 104568, National Aeronautics and Space Administration, Goddard Space Flight Center, Greenbelt, Maryland, USA, doi:10.3334/ORNLDAAC/183, 1992.

Hotanen, J.-P., Nousiainen, H., Mäkipää, R., Reinikainen, A., and Tonteri, T.: Metsätyypit - opas kasvupaikkojen luokitteluun, Metsäkustannus Oy, Porvoo, Finland, 1-192, 2013 (in Finnish).

Ikawa, H., Nakai, T., Busey, R. C., Kim, Y., Kobayashi, H., Nagai, S., Ueyama, M., Saito, K., Nagano, H., Suzuki, R., and Hinzman, L.: Understory $\mathrm{CO}_{2}$, sensible heat, and latent heat fluxes in a black spruce forest in interior Alaska, Agr. Forest Meteorol., 214-215, 80-90, 2015. 
Jakobsons, A.: Sambandet mellan trädkronans diameter och andra trädfaktorer, främst brösthöjdsdiametern: analyser grundade på riksskogstaxeringens provträdsmaterial (the relationship between crown diameter and other tree factors, diameter at breast height in particular: analysis based on the sample tree material of the National Forest Inventory). Stockholms skoghögsskolan, institutionen för skogstaxering (Rapporter och uppsatser 14), 1-75, 1970.

Joint Research Centre, RAdiation transfer Model Intercomparison (RAMI): http://rami-benchmark.jrc.ec.europa.eu/HTML/, last access: 12 October 2016.

Kimes, D. S., Sellers, P. J., and Newcomb, W. W.: Hemispherical reflectance variations of vegetation canopies and implications for global and regional energy budget studies, J. Clim. Appl. Meteorol., 26, 959-972, 1987.

Kirschbaum, M. U. F., Whitehead, D., Dean, S. M., Beets, P. N., Shepherd, J. D., and Ausseil, A.-G. E.: Implications of albedo changes following afforestation on the benefits of forests as carbon sinks, Biogeosciences, 8, 3687-3696, doi:10.5194/bg-83687-2011, 2011.

Korhonen, L.: Estimation of boreal forest canopy cover with ground measurements, statistical models and remote sensing, Dissertationes Forestales, 115, 1-56, 2011.

Kull, O. and Niinemets, U.: Variations in Leaf Morphometry and Nitrogen Concentration in Betula-Pendula Roth, CorylusAvellana L and Lonicera-Xylosteum L, Tree Physiol., 12, 311318, 1993.

Kuusinen, N., Kolari, P., Levula, J., Porcar-Castell, A., Stenberg, P., and Berninger, F.: Seasonal variation in boreal pine forest albedo and effects of canopy snow on forest reflectance, Agr. Forest Meteorol., 164, 53-60, 2012.

Kuusinen, N., Tomppo, E., and Berninger, F.: Linear unmixing of MODIS albedo composites to infer subpixel land cover type albedos, Int. J. Appl. Earth Obs., 23, 324-333, 2013.

Kuusinen, N., Lukeš, P., Stenberg, P., Levula, J., Nikinmaa, E., and Berninger, F.: Measured and modelled albedos in Finnish boreal forest stands of different species, structure and understory, Ecol. Model., 284, 10-18, 2014.

Kuusinen, N., Stenberg, P., Tomppo, E., Bernier, P., Berninger, F., Kuusinen, N., Stenberg, P., Berninger, F., Tomppo, E., and Bernier, P.: Variation in understory and canopy reflectance during stand development in Finnish coniferous forests, Can. J. Forest Res., 45, 1077-1085, 2015.

Kuusinen, N., Stenberg, P., Korhonen, L., Rautiainen, M., and Tomppo, E.: Structural factors driving boreal forest albedo in Finland, Remote Sens. Environ., 175, 43-51, 2016.

Kuusk, A. and Nilson, T.: A directional multispectral forest reflectance model, Remote Sens. Environ., 72, 244-252, 2000.

Lang, M., Kuusk, A., Nilson, T., Lükk, T., Pehk, M., and Alm, G.: Reflectance spectra of ground vegetation in sub-boreal forests, available at: http://www.aai.ee/bgf/ger2600/ last access: 6 February 2013, from Tartu Observatory, Estonia, 2002.

Lang, M., Nilson, T., Kuusk, A., Kiviste, A., and Hordo, M.: The performance of foliage mass and crown radius models in forming the input of a forest reflectance model: A test on forest growth sample plots and Landsat 7 ETM+ images, Remote Sens. Environ., 110, 445-457, 2007.
Liang, J., Zhou, M., Tobin, P. C., McGuire, A. D., and Reich, P. B.: Biodiversity influences plant productivity through nicheefficiency, P. Natl. Acad. Sci. USA, 112, 5738-5743, 2015.

Lukeš, P., Stenberg, P., and Rautiainen, M.: Relationship between forest density and albedo in the boreal zone, Ecol. Model., 261262, 74-79, 2013a.

Lukeš, P., Stenberg, P., Rautiainen, M., Mõttus, M., and Vanhatalo, K. M.: Optical properties of leaves and needles for boreal tree species in Europe, Remote Sens. Lett., 4, 667-676, doi:10.1080/2150704X.2013.782112, 2013b (data available at: http://specchio.ch/, last access: 28 October 2016).

Lukeš, P., Rautiainen, M., Manninen, T., Stenberg, P., and Mõttus, M.: Geographical gradients in boreal forest albedo and structure in Finland, Remote Sens. Environ., 152, 526-535, 2014.

Lukeš, P., Stenberg, P., Mõttus, M., and Manninen, T.: Multidecadal analysis of forest growth and albedo in boreal Finland, Int. J. Appl. Earth Obs., 52, 296-305, 2016.

Majasalmi, T., Rautiainen, M., and Stenberg, P.: Modeled and measured fPAR in a boreal forest: Validation and application of a new model, Agr. Forest Meteorol., 189-190, 118-124, 2014.

Majasalmi, T., Rautiainen, M., Stenberg, P., and Manninen, T.: Validation of MODIS and GEOV1 fPAR Products in a Boreal Forest Site in Finland, Remote Sens., 7, 1359-1379, 2015.

Malone, T., Liang, J., and Packee, E. C.: Cooperative Alaska Forest Inventory. General Technical Report PNW-GTR-785, USDA Forest Service, Pacific Northwest Research Station, 32 Portland, OR, 1-58, 2009.

Manninen, T. and Riihelä, A.: Subarctic boreal forest albedo estimation using ENVISAT ASAR for BRDF determination. Proceedings of IGARSS'08, 6-11 July 2008, CD, 1-4, 2008.

Manninen, T. and Riihelä, A.: ENVISAT/ASAR VV/HH backscattering and the radiation characteristics of Subarctic boreal forest, Proceedings of PolInSAR 2009, 26-30 January 2009, Frascati, Italy, Special publication of ESA SP-668, 1-8, 2009.

Monteith, J. L.: Solar radiation and productivity in tropical ecosystems, J. Appl. Ecol., 9, 744-766, 1972.

Mõttus, M., Stenberg, P., and Rautiainen, M.: Photon recollision probability in heterogeneous forest canopies: Compatibility with a hybrid GO model, J. Geophys. Res.-Atmos., 112, 1-10, 2007.

Naudts, K., Chen, Y., McGrath, M. J., Ryder, J., Valade, A., Otto, J., and Luyssaert, S.: Europe's forest management did not mitigate climate warming, Science, 351, 597-601, 2016.

Ni, W. and Woodcock, C. E.: Effect of canopy structure and the presence of snow on the albedo of boreal conifer forests, J. Geophys. Res., 105, 11879-11888, 2000.

Nilson, T.: Inversion of gap frequency data in forest stands, Agr. Forest Meteorol., 98-9, 437-448, 1999.

Nilson, T. and Peterson, U.: A forest canopy reflectance model and a test case, Remote Sens. Environ., 37, 131-142, 1991.

Packee, E. C., Malone, T., Liang, J., and Stevens, M.: Cooperative Alaska Forest Inventory, Bonanza Creek LTER - University of Alaska Fairbanks, doi:10.6073/pasta/d442e829a1adf7da169b6076826de563, 2010.

Palmroth, S. and Hari, P.: Evaluation of the importance of acclimation of needle structure, photosynthesis, and respiration to available photosynthetically active radiation in a Scots pine canopy, Can. J. Forest Res., 31, 1235-1243, 2001. 
Pan, Y., Birdsey, R. A., Fang, J., Houghton, R., Kauppi, P. E., Kurz, W. A., Phillips, O. L., Shvidenko, A., Lewis, S. L., Canadell, J. G., Ciais, P., Jackson, R. B., Pacala, S. W., McGuire, A. D., Piao, S., Rautiainen, A., Sitch, S., and Hayes, D.: A Large and Persistent Carbon Sink in the World's Forests, Science, 333, 988 993, 2011

Rautiainen, M., Stenberg, P., Nilson, T., and Kuusk, A.: The effect of crown shape on the reflectance of coniferous stands, Remote Sens. Environ., 89, 41-52, 2004.

Rautiainen, M., Suomalainen, J., Mõttus, M., Stenberg, P., Voipio, P., Peltoniemi, J., and Manninen, T.: Coupling forest canopy and understory reflectance in the Arctic latitudes of Finland, Remote Sens. Environ., 110, 332-343, 2007.

Rautiainen, M., Mottus, M., Stenberg, P., and Ervasti, S.: Crown envelope shape measurements and models, Silva Fenn., 42, 1933, 2008.

Rautiainen, M., Mõttus, M., Heiskanen, J., Akujärvi, A., Majasalmi, T., and Stenberg, P.: Seasonal reflectance dynamics of common understory types in a northern European boreal forest, Remote Sens. Environ., 115, 3020-3028, 2011.

Rautiainen, M., Mõttus, M., Yáñez-Rausell, L., Homolová, L., Malenovský, Z., and Schaepman, M. E.: A note on upscaling coniferous needle spectra to shoot spectral albedo, Remote Sens. Environ., 117, 469-474, 2012.

Reich, P. B., Ellsworth, D. S., Walters, M. B., Vose, J. M., Gresham, C., Volin, J. C., and Bowman, W. D.: Generality of leaf trait relationships: A test across six biomes, Ecology, 80, 1955-1969, 1999.

Repola, J.: Biomass equations for birch in Finland, Silva Fenn., 42, 605-624, 2008.

Repola, J.: Biomass equations for Scots pine and Norway spruce in Finland, Silva Fenn., 43, 625-647, 2009.

Richardson, A. D., Berlyn, G. P., and Duigan, S. P.: Reflectance of Alaskan black spruce and white spruce foliage in relation to elevation and latitude, Tree Physiol., 23, 537-544, 2003.

Roujean, J. L.: Measurements of PAR transmittance within boreal forest stands during BOREAS, Agr. Forrest Meteorol., 93, 1-6, 1999.

Schaaf, C. B.: Assessment of the status of the development of the standards for the terrestrial essential climate variables. T8 albedo and reflectance anisotropy, V12, GTOS63, 1-20 NRC, FAO, Rome, 2009.

Serbin, S. P., Ahl, D. E., and Gower, S. T.: Spatial and temporal validation of the MODIS LAI and FPAR products across a boreal forest wildfire chronosequence, Remote Sens. Environ., 133, 7184, 2013.
Sigurdsson, B. D., Thorgeirsson, H., and Linder, S.: Growth and dry-matter partitioning of young Populus trichocarpa in response to carbon dioxide concentration and mineral nutrient availability, Tree Physiol., 21, 941-50, 2001.

Smolander, H., Stenberg, P., and Linder, S.: Dependence of light interception efficiency on structural parameters, Tree Physiol., 14, 971-980, 1994.

Steinberg, D., Goetz, S., and Hyer, E.: Validation of MODIS FPAR products in boreal forests of Alaska, IEEE T. Geosci. Remote, 44, 1818-1828, 2006.

Stenberg, P., Kangas, T., Smolander, H., and Linder, S.: Shoot structure, canopy openness, and light interception in Norway spruce, Plant Cell Environ., 22, 1133-1142, 1999.

Stenberg, P., Linder, S., and Smolander, H.: Variation in the ratio of shoot silhouette area to needle area in fertilized and unfertilized Norway spruce trees, Tree Physiol., 15, 705-712, 1995.

Stoy, P. C., Street, L. E., Johnson, A. V., Prieto-Blanco, A., and Ewing, S. A.: Temperature, heat flux, and reflectance of common subarctic mosses and lichens under field conditions: might changes to community composition impact climate-relevent surface fluxes?, Arct. Antarct. Alp. Res., 44, 500-508, 2012.

Thérézien, M., Palmroth, S., Brady, R., and Oren, R.: Estimation of light interception properties of conifer shoots by an improved photographic method and a 3D model of shoot structure, Tree Physiol., 27, 1375-1387, 2007.

Thuillier, G., Hers, M., Simon, P. C., Labs, D., Mandel, H., and Gillotay, D.: Observation of the solar spectral irradiance from $200 \mathrm{~nm}$ to $870 \mathrm{~nm}$ during the ATLAS 1 and ATLAS 2 missions by the SOLSPEC spectrometer, Metrologia, 35, 689-695, 2003.

Widlowski, J. L., Taberner, M., Pinty, B., Bruniquel-Pinel, V., Disney, M., Fernandes, R., Gastellu-Etchegorry, J. P., Gobron, N., Kuusk, A., Lavergne, T., Leblanc, S., Lewis, P. E., Martin, E., Mõttus, M., North, P. R. J., Qin, W., Robustelli, M., Rochdi, N., Ruiloba, R., Soler, C., Thompson, R., Verhoef, W., Verstraete, M. M., and Xie, D.: Third Radiation Transfer Model Intercomparison (RAMI) exercise: Documenting progress in canopy reflectance models, J. Geophys. Res.-Atmos., 112, 1-28, 2007.

Yang, W., Kobayashi, H., Suzuki, R., and Nasahara, K.: A Simple Method for Retrieving Understory NDVI in Sparse Needleleaf Forests in Alaska Using MODIS BRDF Data, Remote Sens., 6, 11936-11955, 2014.

Yarie, B. J., Kane, E., and Hall, B.: Aboveground Biomass Equations for the Trees of Interior Alaska, AFES Bulletin, 115, 1-16, 2007. 